\title{
The effects of the pyrethroids deltamethrin and cismethrin on nerve excitability in rats
}

\author{
MITSUO TAKAHASHI, ${ }^{*}$ PAMELA M LE QUESNE
}

From The Department of Neurological Studies, The Middlesex Hospital Medical School, London and the MRC Toxicology Unit, Carshalton, Surrey

SUMMARY Deltamethrin produced a prolonged period of increased excitability following the passage of a nerve impulse, which was dose-related and lasted up to $400 \mathrm{~ms}$. Excitability changes were detected without neurological signs following a single IV injection of $0.5 \mathrm{mg} / \mathrm{kg}$ and feeding 200,100 and $50 \mathrm{ppm}$ in the diet for up to 8 weeks. No changes were detected following $0.3 \mathrm{mg} / \mathrm{kg} \mathrm{IV}$ or $25 \mathrm{ppm}$ in the diet. No cumulative effects were detected during chronic feeding. Cismethrin produced increased nerve excitability only between 2 and 4 ms after a nerve impulse. Excitability changes after cismethrin were biphasic during the first $20 \mathrm{~ms}$.

Many synthetic pyrethroid insecticides have been developed in recent years and are likely to be increasingly used, since they combine low mammalian toxicity with high insecticidal activity. They have the additional advantage of being rapidly metabolised. It is well known that their insecticidal action is a direct neurotoxic one, inducing hyperexcitability, tremors and eventual paralysis.

Early studies by Narahashi ${ }^{1}$ demonstrated that during exposure to allethrin, one of the first pyrethroids to be synthesised, a prolonged negative after-potential followed the passage of a nerve impulse. In voltage clamp studies of giant axons, Narahashi and Anderson ${ }^{2}$ showed that this was due to a prolonged inward sodium current. More details of the effect of allethrin and other pyrethroids on ionic movements have since been worked out using similar methods both on giant axons ${ }^{34}$ and on amphibian nodes of Ranvier. ${ }^{5}$ Van den Bercken and Vivjerberg ${ }^{5}$ concluded that deltamethrin held open $m$ (activation) gates of nodes of Ranvier in frog myelinated fibres for a prolonged period. From their work on giant axons, Lund and Narahashi ${ }^{4}$ have concluded that under the influence of tetramethrin a proportion of sodium channels remain normal, but others not only remain open for a prolonged time after a nerve impulse but are

\footnotetext{
* Present address: The Second Department of Internal Medicine, Osaka University Medical School, Japan.
}

Address for reprint requests: Dr PM Le Quesne, The Middlesex Hospital Medical School, London WIN 8AA, UK.

Received 8 June 1982

Accepted 15 July 1982 in an abnormal state when inactive as well as when open. Jacques et $\mathrm{l}^{6}$ have shown that the pyrethroid binding component is distinct from other sodium channel toxin receptors such as batrachotoxin, veratridine and dihydrograyanotoxin II and also from tetrodotoxin.

It was argued in a previous publication ${ }^{7}$ that the effects demonstrated in single fibres would be detectable as activity-related changes in threshold in whole nerve trunks. In normal nerves following the passage of a nerve impulse, excitability is increased for $20 \mathrm{~ms}$ after the end of the relative refractory period (supernormal phase) and a period of reduced excitability (subnormality) follows, lasting up to $200 \mathrm{~ms}$. Following a single high dose of deltamethrin given intravenously excitability was found to be increased to a greater extent and lasted for up to $400 \mathrm{~ms}^{7}$

Following the high dose of deltamethrin used in the previous study, severe abnormal writhing and jerking movements developed within 15 minutes. The effects of lower doses of pyrethroids on nerve excitability have now been studied. If excitability changes can be detected in the absence of clinical abnormalities, then application of the technique described here might have a useful role in the investigation of humans exposed to pyrethroids.

It is important to know whether cumulative effects occur during chronic exposure to pyrethroids. To investigate this possibility, deltamethrin was mixed with the animals' diet at various dose levels and for various lengths of time. Serial studies were carried out during and after administration of the diets.

Two distinct clinical syndromes have been described in rats following exposure to different pyrethroids. ${ }^{89}$ 
The syndrome, consisting of writhing and jerking movements (choreoathetosis) and salivation, produced by deltamethrin has been called the CS syndrome by Verschoyle and Aldridge. ${ }^{9}$ The other syndrome consists of fine, followed by coarse tremors and has been called the $\mathrm{T}$ syndrome. ${ }^{9}$ Although structure-activity relationships are not absolute, the presence of an $\alpha$-cyano group appears to be associated with the CS syndrome. ${ }^{9}$ In the present experiments, in addition to deltamethrin which produces the CS syndrome, cismethrin has been studied as an example of a substance that produces the $\mathrm{T}$ syndrome and has no $\alpha$-cyano group.

\section{Methods}

\section{Animals}

Male Sprague-Dawley rats, ranging in age from 3 to 5 months were used. Anaesthesia for intravenous dosing and electrophysiological study was with "Hypnorm" (Janssen) $0.4-0.5 \mathrm{mg} / \mathrm{kg}$ given intramuscularly as the main anaesthetic, supplemented where necessary by inhalation of a nitrous oxide/oxygen mixture given through a facial mask.

\section{Administration of pyrethroids}

Deltamethrin For intravenous administration, deltamethrin (Roussel) was dissolved in glycerol formal to make solutions containing 2.5 or $5.0 \mathrm{mg} / \mathrm{ml}$. The femoral vein was exposed and the required dose was injected slowly, over 5-10 minutes. For oral administration, deltamethrin was dissolved in $2 \%$ arachis oil and mixed with powdered diet in a commercial food mixer. The animals were allowed free access to food throughout the period of dosing.

Cismethrin For intravenous administration cismethrin (Wellcome) was dissolved in glycerol formal to make a solution containing $10 \mathrm{mg} / \mathrm{ml}$. Slow injection was given into the exposed femoral vein.

\section{Electrophysiology}

The methods used were similar to those described by Parkin and Le Quesne. ${ }^{7}$ The same stimulating and recording apparatus was used, but the stimulating electrodes consisted of thin strips of silver. ${ }^{10}$ These were found to give a better contact with the skin without danger of producing ischaemia than the tinned copper wire electrodes used in the previous study. The subcutaneous temperature of the tail was maintained at 31$35^{\circ} \mathrm{C}$ by heat provided from coiled polythene tubing situated under the tail and containing water pumped from a thermostatically controlled bath.

Two independently variable stimuli were used. S1 was always supramaximal and, as previously, S2 was adjusted to produce a $1 / 3$ maximal response. The time interval between stimuli was varied and at each time interval the amplitude of S1 alone was always measured to ensure that the preparation was stable. Minor fluctuations occurred and the stimulus intensity of S2 was adjusted as necessary. Results of an experiment were rejected if S2 did not remain constant. Statistical comparisons of results were made using Student's $t$ test.

\section{Results}

\section{CONTROL ANIMALS}

The changes in amplitude of $\mathrm{S} 2$ when preceded by $\mathrm{S} 1$ at varying time intervals are illustrated in fig. 1. Forty-two animals were used to establish the control response. The results were similar to those described in the previous study. ${ }^{7}$ Supernormality was present from 4 to $20 \mathrm{~ms}$, the largest response being at $6 \mathrm{~ms}$ when the conditioned response was $120 \%$ of its unconditioned value. Subnormality lasted from 30 to $200 \mathrm{~ms}$. In order to ensure that the solvent for the pyrethroids had no effect on nerve excitability, five animals were given $0 \cdot 1$ ml glycerol formal IV. One hour later excitability changes were the same as in control animals (table 1).

DOSE RESPONSE EFFECTS OF IV DELTAMETHRIN Groups of five animals were given single IV injections of deltamethrin in the following doses: $1 \cdot 5,1 \cdot 0,0 \cdot 75$, $0 \cdot 5,0 \cdot 3 \mathrm{mg} / \mathrm{kg}$.

\section{Clinical features}

Following injection of $1.5 \mathrm{mg} / \mathrm{kg}$, excess salivation began within five minutes, followed by severe abnormal movements, consisting of coarse whole body tremors with writhing and jerking movements of the limbs and trunk (the CS syndrome as described by Verschoyle and Aldridge). ${ }^{9}$ Following injection of $1 \cdot 0$ and $0.75 \mathrm{mg} / \mathrm{kg}$, salivation occurred as after the higher dose but the abnormal movements were less intense. Because of the intensity of the movements electrophysical studies could not be carried out during the first few hours after injection. These animals were therefore studied after five hours. Following administration of $0.5 \mathrm{mg} / \mathrm{kg}$, two out of five animals developed excessive salivation, but none of them had any abnormal movements. These animals were examined at one and five hours after injection. No clinical abnormalities were detected in any of the animals given $0.3 \mathrm{mg} / \mathrm{kg}$, which were examined after one hour.

\section{Electrophysiological findings}

Excitability changes observed five hours after injection of $1.5 \mathrm{mg} / \mathrm{kg}$ are shown in fig 1 compared with those in control animals. The results are very similar to those found previously by Parkin and Le Quesne. ${ }^{7}$ The peak of supernormality occurred at $6 \mathrm{~ms}$ in both deltamethrin and control groups. However the mean value at $6 \mathrm{~ms}$ for five deltamethrin animals was 141 (SD $15.7) \%$, compared with a mean value of 120 (SD $11.5) \%$ for 42 control animals. The difference was highly significant $(p<0 \cdot 001)$. Supernormality persisted for up to $400 \mathrm{~ms}$.

The results for the different doses of deltamethrin are shown in table 1 and fig 2 from which it can be seen that there was a clear dose-response effect. The 


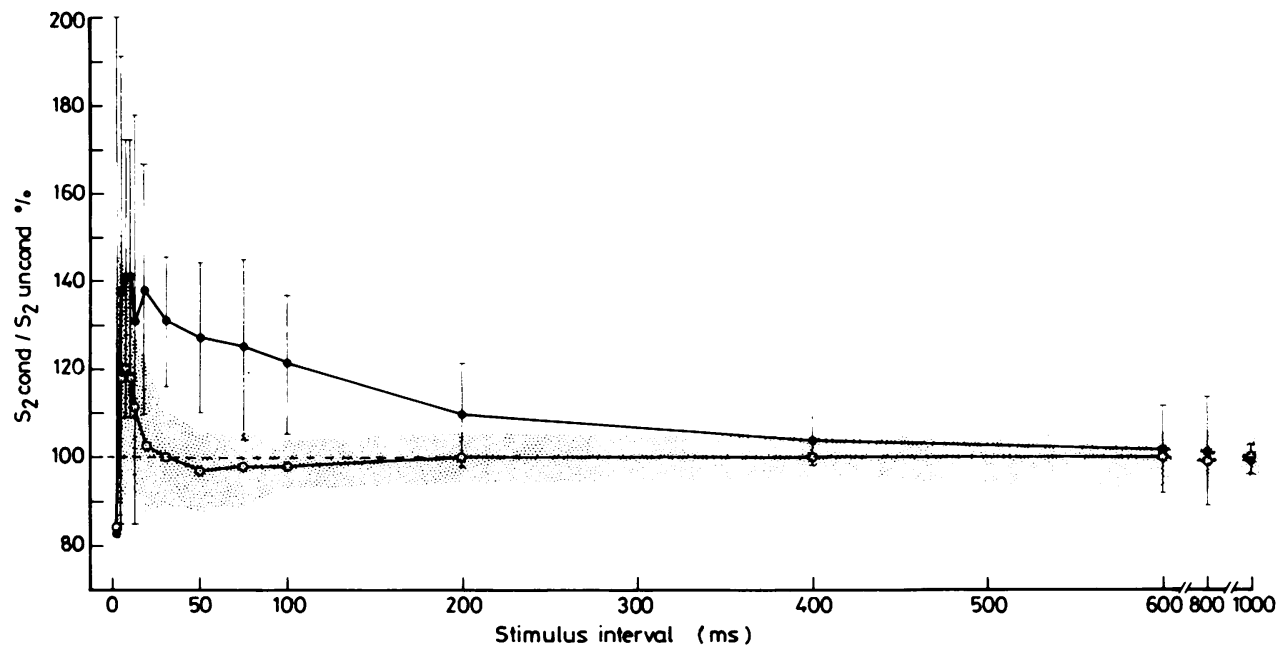

Fig 1 Percentage change in amplitude of response to a submaximal stimulus when preceeded by a supramaximal conditioning stimulus at varying time intervals. Open circles-mean results for 42 control animals; closed circles-mean results for 5 animals 5 h after $1.5 \mathrm{mg} / \mathrm{kg}$ IV deltamethrin. Stippled area denotes $+2 S D$ from mean in control animals; vertical lines $+2 S D$ from mean in deltamethrin-treated animals.

differences between the groups were most evident at stimulus intervals between 30 and $100 \mathrm{~ms}$. In order to increase the number of values for statistical comparison of the effects of different doses, the results at four time intervals $(30,50,75$ and $100 \mathrm{~ms})$ have been combined and the results are shown in table 1 . Prolongation of increased excitability was evident at five hours in animals given $1 \cdot 5,1 \cdot 0$, or $0 \cdot 75$ $\mathrm{mg} / \mathrm{kg}$. Although no neurological abnormalities developed following $0.5 \mathrm{mg} / \mathrm{kg}$, prolonged supernormality was detected one hour after injection but not after five hours. No clinical or electrophysiological abnormalities were detected one hour after $0.3 \mathrm{mg} / \mathrm{kg}$.

Five animals were examined 24 hours after $1.5 \mathrm{mg} / \mathrm{kg}$. A slight persistent effect was detected at this time $(\mathrm{p}<$ $0 \cdot 05)$ (table 1).

\section{CHRONIC EXPOSURE TO DELTAMETHRIN}

Groups of animals were given a diet containing deltamethrin in the following concentrations: 200,100 , 50 and $25 \mathrm{ppm}$ for up to eight weeks. No clinical abnormality was detected in any of the animals.

Electrophysiological studies were carried out at intervals during dosing and some animals were examined one or two days after returning to a normal diet. The mean results after one week on different diets are shown in fig 3. There was no increase in supernormality at short stimulus intervals up to $20 \mathrm{~ms}$. The results for four combined stimulus intervals, 30 $100 \mathrm{~ms}$, are shown in table 2 . Increased excitability was present in animals fed 200,100 and $50 \mathrm{ppm}$, but not in those given $25 \mathrm{ppm}$.

After one week, excitability was increased significantly more in animals fed 200 ppm than those

Table 1 Effects of IV deltamethrin. The values shown are combined results for stimulus intervals $30,50,75$ and $100 \mathrm{~ms}$. Clinical signs were graded: +++ excess salivation and choreoathetosis; ++ excess salivation and mild abnormal movements; + excess salivation only; — no abnormal signs. $p^{*}$ — statistical comparison with control; $p^{* *}$ — statistical comparison with next higher dose.

\begin{tabular}{|c|c|c|c|c|c|c|}
\hline $\begin{array}{l}\text { Dose } \\
m g / k g\end{array}$ & $\begin{array}{l}\text { Clinical } \\
\text { signs }\end{array}$ & $\underset{(h)}{\text { Time }}$ & $n$ & $\begin{array}{l}\text { S2 cond } / S 2 \text { uncond } \\
\%(S D)\end{array}$ & $p^{*}$ & $p^{* *}$ \\
\hline $\begin{array}{l}1 \cdot 5 \\
1 \cdot 0 \\
0 \cdot 75 \\
0.5 \\
0 \cdot 5 \\
0.3 \\
1 \cdot 5 \\
\text { Glycerol formal } \\
\text { Control }\end{array}$ & $\begin{array}{l}+++ \\
++ \\
++ \\
- \\
+ \text { or }- \\
- \\
- \\
-\end{array}$ & $\begin{array}{r}5 \\
5 \\
5 \\
5 \\
1 \\
1 \\
24 \\
1\end{array}$ & $\begin{array}{r}20 \\
20 \\
20 \\
20 \\
24 \\
20 \\
20 \\
20 \\
165\end{array}$ & $\begin{array}{r}125 \cdot 8(8 \cdot 7) \\
106.7(5 \cdot 5) \\
104 \cdot 0(3 \cdot 8) \\
99 \cdot 4(5 \cdot 5) \\
104.4(4 \cdot 8) \\
99 \cdot 7(4 \cdot 5) \\
100.6(3.2) \\
96.8(6.7) \\
98 \cdot 4(4 \cdot 4)\end{array}$ & $\begin{array}{l}<0.001 \\
<0.001 \\
<0.001 \\
>0.1 \\
<0.001 \\
>0.1 \\
<0.05 \\
>0.1\end{array}$ & $\begin{array}{l}<0.001 \\
>0.05 \\
<0.01 \\
<0.01\end{array}$ \\
\hline
\end{tabular}




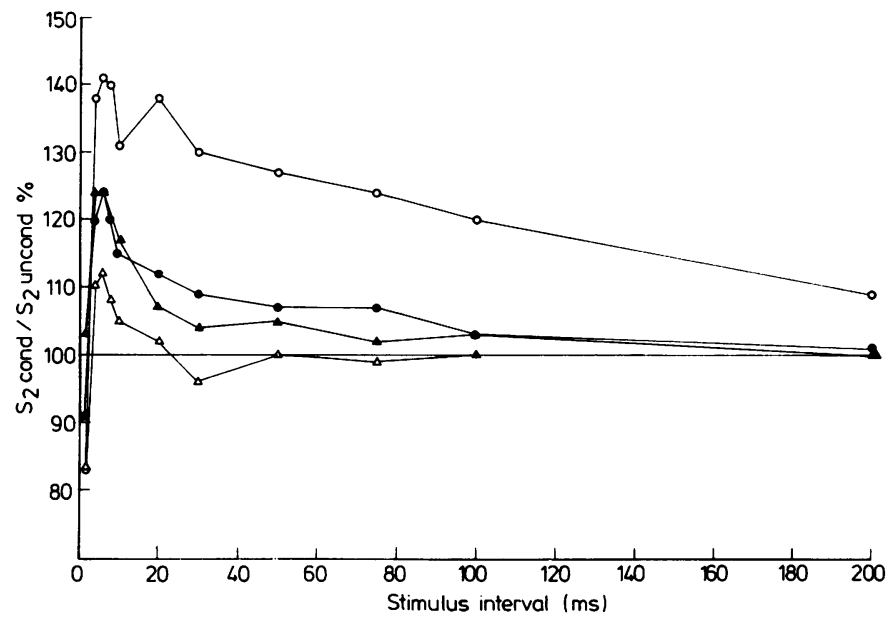

Fig 2 Mean excitability changes in groups of 5 rats $5 \mathrm{~h}$ after $I V$

deltamethrin. $O-1.5 \mathrm{mg} / \mathrm{kg} ; 0-1.0 \mathrm{mg} / \mathrm{kg} ; \Delta-0.75 \mathrm{mg} / \mathrm{kg} ; \triangle-0.5$ $\mathrm{mg} / \mathrm{kg}$.

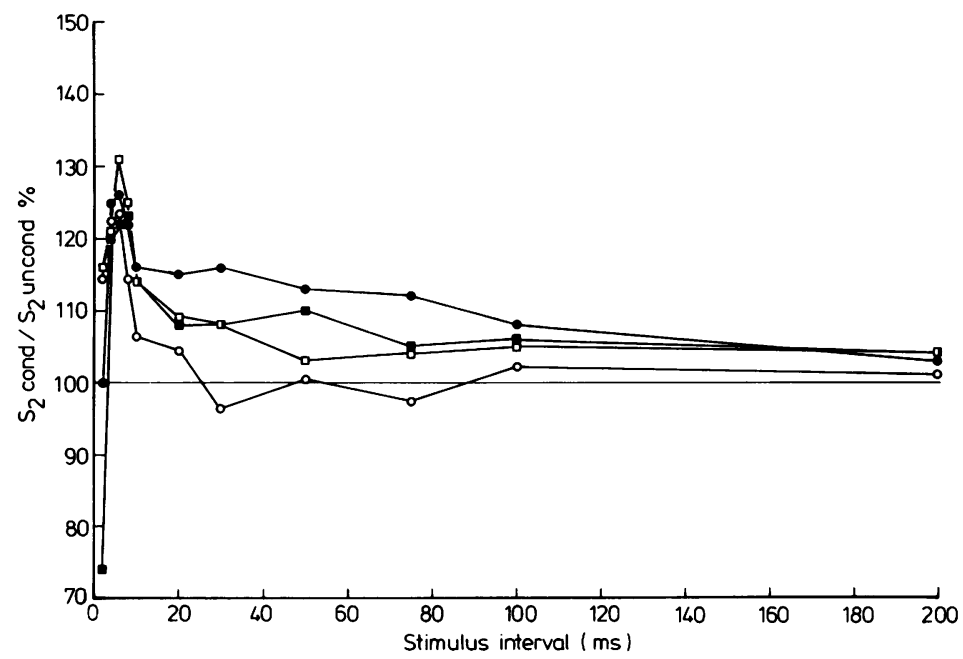

Fig 3 Mean excitability changes after 1 week chronic feeding of deltamethrin. -11 animals given 200 ppm; -4 animals given 100 ppm; $\square-4$ animals given 50 ppm; $0-5$ animals given 25 ppm.

given $100 \mathrm{ppm}(\mathrm{p}<0 \cdot 05)$. Although the effect was less in animals fed 50 than $100 \mathrm{ppm}$, the results were not significantly different.

In animals fed 200,100 and $50 \mathrm{ppm}$ abnormalities did not increase with time. Indeed changes were slightly less marked after four weeks than after one week, but significant differences were only found for the 200 ppm group $(\mathrm{p}<0 \cdot 01)$. No electrophysical abnormality was detected $24-48$ hours after return to a normal diet.

\section{CISMETHRIN}

\section{Clinical features}

Seven animals given $0.3 \mathrm{mg} / \mathrm{kg}$ IV cismethrin developed a different type of neurological disorder from that produced by deltamethrin. Within two 
Table 2 Effects of exposure to different concentrations of deltamethrin in the diet for one week. The values shown are combined results for stimulus intervals $30,50,75$ and $100 \mathrm{~ms}$. Statistical comparison with control value: ${ }^{* *}=p<0.001 ;{ }^{*}=p$ $<0.05 ;$ NS = not significant.

\begin{tabular}{|c|c|c|c|c|c|c|c|c|}
\hline Time & $\begin{array}{l}\text { Dose } \\
n\end{array}$ & $\begin{array}{l}200 \text { ppm } \\
S 2 \text { cond } 1 \\
S 2 \text { uncond } \\
\%(S D)\end{array}$ & $n$ & $\begin{array}{l}100 \text { ppm } \\
\text { s2 cond/ } \\
S 2 \text { uncond } \\
\%(S D)\end{array}$ & $n$ & $\begin{array}{l}50 \text { ppm } \\
\text { S2 cond / } \\
S 2 \text { uncond } \\
\%(S D)\end{array}$ & $n$ & $\begin{array}{l}25 \text { ppm } \\
S 2 \text { cond } / \\
S 2 \text { uncond } \\
\%(S D)\end{array}$ \\
\hline $\begin{array}{l}2 \text { days } \\
1 \text { week } \\
4 \text { weeks } \\
8 \text { weeks } \\
1 \text {-2 days after } \\
\text { Control }\end{array}$ & $\begin{array}{r}16 \\
44 \\
40 \\
20 \\
36 \\
165\end{array}$ & $\begin{array}{l}115.8(13.0)^{* *} \\
112.5(7.8)^{* *} \\
107.9(7.4)^{* *} \\
110.2(4.4)^{* *} \\
99.4(3.9) \mathrm{NS} \\
98.4(4.4)\end{array}$ & $\begin{array}{l}16 \\
16\end{array}$ & $\begin{array}{l}107 \cdot 8(4 \cdot 2)^{* *} \\
104 \cdot 6(6 \cdot 0)^{* *}\end{array}$ & $\begin{array}{l}16 \\
16\end{array}$ & $\begin{array}{l}105 \cdot 7(6 \cdot 3)^{* *} \\
103 \cdot 3(3 \cdot 2)^{* *}\end{array}$ & 20 & $99.2(3.6) \mathrm{NS}$ \\
\hline
\end{tabular}

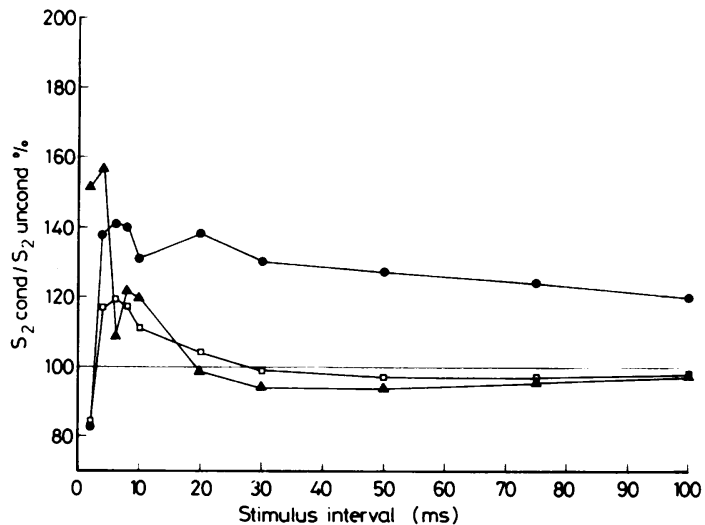

Fig 4 Mean excitability changes in -5 animals 5 h after $1.5 \mathrm{mg} / \mathrm{kg} / \mathrm{V}$ deltamethrin; $\boldsymbol{\Delta}-7$ animals $5 \mathrm{~h}$ after 3.0 mg/kg IV cismethrin; $\square-42$ control animals.

minutes of the injection fine whole body tremor developed and the animals became hypersensitive to sounds and touch ( $\mathrm{T}$ syndrome of Verschoyle and Aldridge). ${ }^{9}$ No excessive salivation or abnormal movements of the type seen after deltamethrin occurred. Following the dose used in the present study, marked tremors continued for about one hour and then gradually subsided within the next five hours.

\section{Electrophysiological findings}

The mean results are shown in fig 4 where the findings five hours after cismethrin administration are compared with those following the highest dose of deltamethrin and control animals. It can be seen that cismethrin also caused an increased excitability, but that this occurred at short stimulus intervals only. At 2 ms, S2 conditioned/S2 unconditioned was 153 (SD $39.2) \%$ in cismethrin treated animals, whereas nerves were still partially refractory in control animals. (S2 conditioned/S2 unconditioned: 84 (SD 28.5)\%.) At 4 ms the value for cismethrin animals was 158 (SD

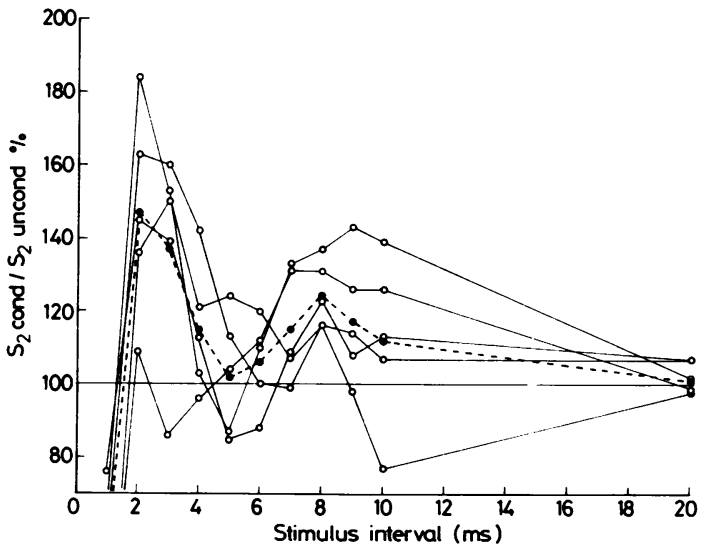

Fig 5 Excitability changes $1 \mathrm{~h}$ after $3.0 \mathrm{mg} / \mathrm{kg}$ cismethrin. — values for individual animals; - mean values.

30.0)\% compared with 118 (SD $16 \cdot 1) \%$ for control animals. In both instances the differences were highly statistically significant $(p<0.001)$. Subnormal excitability was present with stimulus intervals of 30 to $200 \mathrm{~ms}$ as in control animals.

A striking feature of the excitability changes following cismethrin was the biphasic increased excitability response in the first $20 \mathrm{~ms}$ (fig 5). It can be seen that there was considerable individual variation between animals. In some in whom excitability was within the range of that seen in control animals at all time intervals, there was nevertheless a biphasic response. This was never seen in control animals.

\section{Discussion}

Following a single intravenous dose of deltamethrin, a clear dose-response effect has been demonstrated on the prolongation of excitability following a nerve impulse. The no-effect level for excitability changes was $0.3 \mathrm{mg} / \mathrm{kg}$ single IV dose and exposure to $25 \mathrm{ppm}$ 
in the diet. Some electrophysiological effect could still be detected below levels which produced clinically detectable neurological changes, both following a single dose $(0.5 \mathrm{mg} / \mathrm{kg})$ and chronic feeding $(200,100$ and $50 \mathrm{ppm})$. The technique may therefore be sufficiently sensitive to be valuable in studying humans with suspected toxicity.

As in the previous study by Parkin and Le Quesne ${ }^{7}$ a slight persistent effect was detected 24 hours after a single injection of $1.5 \mathrm{mg} / \mathrm{kg}$ deltamethrin.

In animals receiving deltamethrin in their diet there was a tendency for electrophysiological abnormalities to decrease with time. However no accurate measurement of food intake was made for individual animals and so no record is available of the actual quantity of deltamethrin consumed. Our impression was that the amount of food eaten did fall slightly. In order to study changes on constant exposure, more accurate control of intake would be necessary. However, in the present study there was no suggestion of any cumulative effect nor of any persistent effect when exposure ceased.

Deltamethrin and cismethrin were studied as examples of pyrethoids which produce different clinical syndromes, either the CS or the T syndrome. It has been suggested that the different effects depend on the presence (CS syndrome) or absence ( $T$ syndrome) of an $\alpha$-cyano group in the pyrethroid molecule. ${ }^{9}$ Different physiological effects have also been described between the two groups of pyrethroids. Narahashi" has commented that in giant axons, compounds without an $\alpha$-cyano group for example tetramethrin and allethrin, increase the depolarising after-potential and induce repetitive firing to a single stimulus. On the other hand those with an $\alpha$-cyano group, for example deltamethrin, produce membrane depolarisation without electrical stimulation. $\mathrm{He}$ argues that both effects could result from a similar action on sodium channels, but differing in degree. Vivjerberg and Van den Bercken ${ }^{12}$ showed that deltamethrin had a much more prolonged effect on the sodium tail current in voltage clamp studies of frog myelinated nodes of Ranvier (up to $1 \mathrm{~s}$ ) than pyrethroids such as allethrin with no $\alpha$-cyano group, which prolonged the tail current for less than $100 \mathrm{~ms}$. As predicted from these observations, deltamethrin had a very prolonged effect on nerve excitability as demonstrated by the technique used here, whereas cismethrin increased excitability only during the first few milliseconds.

Following cismethrin, a biphasic change in excitability was present within the first 20 ms. This never occurred in control animals. The reasons for this are obscure. It could be postulated that it was due to an interaction of the factors responsible for increased excitability in normal nerve and those producing the pyrethroid-induced increased excitability.

There is still some doubt as to the site of origin of abnormal neurological signs. The abnormal movements in the CS syndrome clearly originate in the central nervous system. Both electrophysiological and biochemical abnormalities have been demonstrated in the brain following deltamethrin administration. ${ }^{1314}$ The origin of tremor in the T syndrome is uncertain. A peripheral nerve origin has been suggested ${ }^{9}$ but this has been questioned by Gray et al $^{15}$ who produced tremor by intracerebral injection. Whatever the origin of neurological abnormalities, the present study has shown a clear effect of both types of compound on peripheral nerve origin has been suggested ${ }^{9}$ but this effect on nerve membranes.

We would like to thank Mr Tarlok Gajree for his assistance. MT was in receipt of a grant from the Japanese Ministry of Education for which he is grateful.

\section{References}

${ }^{1}$ Narahashi T. Mode of action of pyrethroids. Bull WHO 1971;44:337-45.

${ }^{2}$ Narahashi T, Anderson NC. Mechanism of excitation block by the insecticide allethrin applied externally and internally to squid giamt axon. Toxicol App Pharmacol 1967;10:529-47.

${ }^{3}$ Lund AE, Narahashi T. Modification of sodium channel kinetics by the insecticide tetramethrin in crayfish giant axons. Neurotoxicology 1981;2:213-29.

${ }^{4}$ Lund AE, Narahashi T. Kinetics of sodium channel modification by the insecticide tetramethrin in squid axon membranes. $J$ Pharmacol Exp Ther 1981;219:464-73.

${ }^{5}$ Van den Bercken J, Vivjerberg HPM. Voltage clamp studies on the effects of allethrin and DDT on the sodium channels in frog myelinated membrane. In: Insect Neurobiology and Pesticide Action. London: Soc Chem Ind, 1980:79-85.

${ }^{6}$ Jacques Y, Romey G, Cavey MT, Kartalovski B, Lazdunski M. Interaction of pyrethroids with the $\mathrm{Na}^{+}$ channel in mammalian neuronal cells in culture. Biochem Biophys Acta 1980;600:882-97.

${ }^{7}$ Parkin PJ, Le Quesne PM. Effect of a synthetic pyrethroid deltamethrin on excitability changes following a nerve impulse. J Neurol Neurosurg Psychiatry 1982;45:337-42.

${ }^{8}$ Barnes LM, Verschoyle RD. Toxicity of new pyrethroid insecticide. Nature 1974;248:711.

${ }^{9}$ Verschoyle RD, Aldridge WN. Structure-activity relationships of some pyrethroids in rats. Arch Toxicol 1980;45:325-29.

${ }^{10}$ Takahashi M. Electrophysiological studies on peripheral nerve lesions in myeloneuropathy with gastrointestinal disorders. Nippon Naika Gakkai Zasshi 1970;59:614 22.

"Narahashi T. Site and types of action of pyrethroids on nerve membrane. In: Pyrethroid insecticides: chemistry 
and action. Table Ronde Roussel UCLAF, Paris: Roussel, 1980:15-7.

12 Vivjerberg HPM, Van den Bercken J. Frequencydependent effects of the pyrethroid insecticide decamethrin in frog myelinated nerve fibres. Eur $J$ Pharmacol 1979;58:501-4.

${ }^{13}$ Ray DE. An EEG investigation of decamethrin-induced choreoathetosis in the rat. Exp Brain Res 1980;38:2217. it Cremer JER, Cunningham VJ, Ray DE, Gurcharan SS. Regional changes in brain glucose utilisation in rats given a pyrethroid insecticide. Brain Res 1980;194:27882.

${ }^{15}$ Gray AJ, Connors TA, Hoellinger H, Nguyen-HoangNam. The relationship between the pharmacokinetics of intravenous cismethrin and bioresmethrin and their mammalian toxicity. Pestic Biochem Physiol 1980;13:281-93. 